\title{
The Impact on Self Perception of Ego States of a Transactional Analysis Introductory Training Course (TA 101)
}

\section{(C) 2011 Traian Bossenmayer}

\begin{abstract}
The research examines the effects of transactional analysis (TA) 101 training upon self perceptions of ego-state dynamics, using the model of ego states incorporated into the Adjective Check List (Gough \& Heilbrun, 1980). Subjects completed the questionnaires at the beginning and end of the training and one month later. The only statistically significant change was that Critical Parent decreased after the training and was still lowered one month later, although not as much. It was also found that gender was significant, but age was not.
\end{abstract}

\section{Key words}

transactional analysis (TA), TA 101, ego states, Critical Parent, Adjective Check List.

\section{Introduction}

Many of the problems that occur in organisations are the direct result of people failing to communicate. Faulty communication causes a series of problems and it can lead to confusion and cause a good plan to fail (Pearson, 1983). Employees who are trained in transactional analysis theory might develop their skills in analysing transactional patterns and could be able to understand, predict and help improve dysfunctional, unproductive, uncooperative interactions between them-selves and their colleagues. In the TA literature it is assumed that TA training can help them communicate clearly and effectively at the three levels of the Parent (values) the Adult (rationality) and the Child (emotions, creativity) (Steiner, 1994).

The goal of this research was to test whether people who participated in a TA 101 training session (the introductory course in transactional analysis) had any changes in their pattern of ego-state behaviour. The research focused on the differences that might occur for each separate ego state at three different points in time. The positive effects of group therapy on egostate change and ego-state perception was confirmed by Boholst's (2003) research on a group of 28 university students using the Adjective Check List questionnaire, the same method used in this research. The TA 101 course was chosen because of its standardised content and requirement that it is run only by internationally-endorsed trainers, under the overall control of the International Transactional Analysis Association (ITAA) and the European Association for Transactional Analysis (EATA).

The majority of the participants of the TA 101 course are new to TA concepts, so the effects of the TA training can be observed in a more effective way. For this specific research a control variable was used to evaluate the differences between the TA 101 participants who already had some TA knowledge (from previous diverse trainings) and those who were encountering TA for the first time.

Ego states: description and relevance for TA Ego states represent one of the building blocks of TA theory. All transactional analysts work with ego states, which cover important personality features and are considered to be essential characteristics of TA therapy (Dusay, 1986).

In the early three ego-state models, the Parent is a language of values, the Adult is a language of logic and rationality, and the Child is a language of emotions. Creating an effective communication depends on the availability of all three intact ego states (Steiner, 1994). However, there are various models of ego states in use (Erskine \& Trautmann, 1981, 1988; Van Beekum, 1996; Hargaden \& Sills 2002; Hay, 2009) and it is recognised that this study is focused on behavioural diagnosis of ego states only.

The questionnaire used (Williams \& Williams, 1980) is divided into five parts corresponding to the functional five ego-state model. Each ego state is regarded as a system of communication with its own distinct language and function (Steiner, 2011).

\section{Research question}

The research set out to test the effects of the TA 101 training on the ego states of the participants by measuring the ego states at three different points in time: right before the training (TO), right after the training session ended on the second day (T1), and one month after the training (T2). 
Based on this overall question, three hypotheses were derived:

Hypothesis 1. There will be a change of the dominant ego states from $T 0$ to $T 1$

Hypothesis 2. There will be a change of the dominant ego states from $T 1$ to $T 2$

Hypothesis 3. There will be a change of the dominant ego states from T0 to T2

These overall hypotheses converted into five sets to match the five ego states that were being measured in the questionnaire used.

Three control variables were used: the age of the respondents, the gender, and whether they had any past training in TA. It was noted that the way that ego states manifest is not related to age. This means that a 60-year-old person can act as a Free Child and a 12-year-old child can act as a Critical Parent.

\section{Research design}

The research design was a pre-and post-intervention study with a follow-up measurement to check stability of change. The ego states of the subjects were measured before the training (T0), at the end of the training (T1) and one month after the training had ended (T2). The data was collected using a questionnaire and the participants were chosen from three different TA training sessions, all of them taking place in The Netherlands. Three control variables were used to get a better insight into the factors influencing these changes. The hypotheses were analysed using the student $t$ test. To analyse the influences of the control variables on the differences between the means of each ego state, a multiple linear regression was used. Prior to this a bivariate analysis was used to check for correlations between the control variables and the differences in the ego state between the different points in time.

\section{Data collection}

The assessed variable was the distribution of ego states for each participant at each of the time-points, measured using the TA sub-scales developed by Williams \& Williams (1980) from the Adjective Check List (Gough \& Heilbrun, 1980). Each participant received a list of adjectives which she/he scored as being characteristic for her/him; each ego state was derived by combining some of these adjectives; for instance, the Free Child ego state is a combination of 13 adjectives (e.g. adventurous, imaginative). The use of the Adjective Check List (ADL) scale was considered appropriate because adjectives were also commonly used by Berne (1967) to describe ego states. Also, this scale is academically validated.

The first two series of questionnaires, corresponding to T0 and T1, were collected directly from the trainers at the end of the sessions or were sent by mail. The third series, corresponding to T2, were collected by sending individual emails to each training participant. The rate of response in T2 was lower compared to T0 and $\mathrm{T} 1$.

Data analysis

Given the fact that the same subjects were analysed three times and that the interest was to see if there were any differences from one time point to another in the ego states, a multiple linear regression was used. This offered the possibility of analysing the interaction of the control variables (age, gender, prior TA training) on each ego state. Before this technique was applied, the average of each scale for each ego state per individual was calculated (for T0, T1, T2). Then the difference between the means (T1-T0, T2-T0, T2-T1) was used as a dependent variable in the multiple regression, with Cronbach's alpha of 0.6 applied as a criterion.

Sample strategy

A random sample is desirable in any research in order to be able to generalise the results to the whole population from which the sample has been drawn. However, this was not possible in this study. The sample consisted of 38 people who were participating in the TA 101 trainings in The Netherlands in recent months. It had been hoped to have a sample of 100 people but this was not possible due to the lack of availability of TA 101 courses running during the limited time available for the research. The criteria for selection were the accessibility and the openness for medium-term investigation of the participants.

\section{Research quality indicators}

\section{Reliability}

Statistical reliability measures were used to ensure the reliability of the scales within the questionnaire (Cronbach's alpha 0.6). The reliability of the research is increased by the use of a standardised questionnaire and also by the standardised TA 101 training context and procedures which ensure a broadly similar learning experience and content for the participants.

\section{Internal validity}

One way in which the quality of the research can be verified is by examining the psychometrical proprieties of the questionnaire. In this sense the distinctiveness sections measuring the five different ego states can be checked with the use of factorial analysis. Also, the questionnaire was academically validated through the study of Williams (1980) by using an expert panel of 15 transactional analysts. It was confirmed that each section was referring to a separate ego state and that the results of the questionnaire could be represented by the egogram developed by Dusay (1972).

Williams also mentions that the questionnaire was designed in order to offer an alternative for evaluating the strength of the ego states of participants who were 
not familiar with TA concepts. Up to that point all the instruments of measuring the ego states were based on TA knowledge of the respondents. Taking into account that the majority of the TA 101 participants are new to the field of transactional analysis, the Adjective Check List questionnaire was the best suited method. The control variable of prior TA training was introduced in the study for the same reason. From the total number of 38 participants, only five had prior TA knowledge.

\section{Results}

The five hypotheses for each time frame focus on the changes of each ego state from T0 (before the training), T1 (right after the course has ended) and T2 (one month after the training has ended). The results shown here are for Critical Parent only; the same processes were completed for each ego state but are not shown as they were not statistically significant. The data are available from the author for future researchers.

\section{Descriptive statistics}

Table 1 includes the information about the TA 101 training regarding the number of participants, gender, age, and prior TA training. There were 38 participants initially, ranging in age from 20 to 58 years, with an average age of 40 years. Only five of them had previous knowledge of TA concepts from other training sessions (not TA 101).

The data was collected from three different TA 101 training courses. For T0 (before the training) the total number of 38 participants (30 female, 8 male) filled in the questionnaires. For T1 (right after the training) there were 31 (24 female, 7 male) answered questionnaires because one trainer did not hand in their questionnaires. For T2 (one month after each training session) the participants were contacted by email. Only ten participants ( 3 female, 7 male) answered the emails and filled in the questionnaires.

Therefore the data for analysing the ego-state changes between T0 (before the training) and T1 (right after the session) come from 31 participants. The data for analysing the changes between T0 (before the training) and T2 (one month after the training) come from ten participants (maximum number of questionnaires for T2). The data for analysing the changes between T1 (right after the session) and T2 (one month after the training) come also from ten participants.

Table 1: Descriptive statistics

\begin{tabular}{lrrrrr}
\hline & Number & Minimum & Maximum & Mean & Std. deviation \\
\hline gender & 38 & 1,00 & 2,00 & 1,2105 &, 41315 \\
age & 38 & 20,00 & 58,00 & 40,1316 & 10,31968 \\
\hline TA training & 38 & 1,00 & 2,00 & 1,8684 &, 34257 \\
\hline CP T0 & 38 & 1,15 & 3,77 & 2,4798 &, 55569 \\
NP T0 & 38 & 2,54 & 4,77 & 3,7773 &, 47141 \\
AD T0 & 38 & 2,77 & 4,46 & 3,5162 &, 41401 \\
AC T0 & 38 & 1,46 & 3,38 & 2,4717 &, 52361 \\
FC T0 & 38 & 1,92 & 4,42 & 3,4035 &, 56404 \\
\hline CP T1 & 31 & 1,38 & 3,92 & 2,4194 &, 62044 \\
NP T1 & 31 & 2,69 & 4,77 & 3,8362 &, 47325 \\
AD T1 & 31 & 2,77 & 4,38 & 3,5112 &, 45184 \\
AC T1 & 31 & 1,38 & 3,23 & 2,3573 &, 48996 \\
FC T1 & 31 & 2,33 & 4,50 & 3,4892 &, 42259 \\
\hline CP T2 & 10 & 1,08 & 3,15 & 2,0846 &, 63479 \\
NP T2 & 10 & 3,00 & 4,92 & 3,7846 &, 55919 \\
AD T2 & 10 & 2,54 & 4,08 & 3,4846 &, 46161 \\
FC T2 & 3,00 & 4,17 & 3,4417 &, 35366 \\
AC T2 & 10 & 3,08 & 2,1692 &, 64133 \\
\hline
\end{tabular}

Note. $\mathrm{CP}=$ Critical Parent, $\mathrm{NP}=$ Nurturing Parent, $\mathrm{AD}=$ Adult, $\mathrm{AC}=$ Adapted Child, $\mathrm{FC}=$ Free Child 
The scales are valid, the alpha Cronbach for all the five types of ego states are above 0.6. The data for the three time points are shown in Table 2.

Table 2: Alpha Cronbach for T0, T1, T2

\begin{tabular}{|c|c|c|c|}
\hline & TO & T1 & T2 \\
\hline Critical Parent & 0.831 & 0.904 & 0.930 \\
\hline Nurturing Parent & 0.851 & 0.894 & 0.935 \\
\hline Adapted Child & 0.711 & 0.823 & 0.860 \\
\hline Free Child & 0.836 & 0.756 & 0.654 \\
\hline Adult & 0.824 & 0.831 & 0.922 \\
\hline
\end{tabular}

\section{Analysis of the hypotheses}

Before analysing each hypothesis using the student ttest, a bivariate analysis was used to compare the control variables (gender, age, prior TA training) with the changes in each ego state, to see if the variations in the values of the control variables are systematically associated with the variations in the ego states and to get a better insight on the interaction effect between them.

Table 3 includes the correlations between age and prior TA training and changes for each ego state at the three different points in time (T0, T1 and T2). The calculation for gender could be done at T0 only.

As we can see, for the Critical Parent the control variable gender was significantly correlated with the changes in the ego state. Therefore, in the Critical Parent results section, below, a separate $t$ test analysis was run to see if the scores of the Critical Parent changed in a different way among males and females and whether these changes were significant or not. The results of the student t-test are shown in Table 4

For the Adapted Child the control variable age was significantly correlated with the changes in the ego state but the number of respondents in this case was low (10) so it was not feasible to split the sample into different age groups and compare them.
Table 3: Control variables - changes in the Critical Parent (CP)

\begin{tabular}{|c|c|c|c|c|}
\hline & & $\begin{array}{l}\text { CP } \\
\text { T0 }\end{array}$ & $\begin{array}{l}\text { CP } \\
\text { T1 }\end{array}$ & $\begin{array}{l}\text { CP } \\
\text { T2 }\end{array}$ \\
\hline \multirow{3}{*}{ gender } & Pearson Correlation & $.482^{* *}$ &.$a$ & a \\
\hline & Sig. (2-tailed) & .006 & .000 & .000 \\
\hline & Number & 31 & 10 & 10 \\
\hline \multirow{3}{*}{ age } & Pearson Correlation & .257 & .017 & -.093 \\
\hline & Sig. (2-tailed) & 163 & 963 & .799 \\
\hline & Number & 31 & 10 & 10 \\
\hline \multirow{3}{*}{$\begin{array}{c}\text { TA } \\
\text { training }\end{array}$} & Pearson Correlation & 156 & .041 & -.062 \\
\hline & Sig. (2-tailed) & .403 & .911 & .864 \\
\hline & Number & 31 & 10 & 10 \\
\hline
\end{tabular}

Note. ${ }^{* *}$ Correlation is significant at the 0.01 level (2-tailed);

.a cannot be computed because at least one of the variables is constant.

\section{Changes in the Critical Parent}

Hypothesis 1: There will be a drop in Critical Parent (CP) ego-state at T1 (end of the training) compared to T0 (beginning of the training).

Hypothesis 0: CP T0 = CP T1

Hypothesis 1: CP T0 > CP T1

The $t=2.473$ from the table is higher than the standard value of $t$ when Alpha is .05 and also that $p$ of .019 is lower than .05 , the null hypothesis is rejected. Therefore the analysis confirms with a probability of $95 \%$ that there is a drop of the Critical Parent ego state from T0 to T1.

The decrease of the ego state from T0 to T1 is also shown in Figure 1, the 'Critical Parent' graph and the difference of means is 0.17 .

A multiple linear regression was completed to analyse the effects of the control variables on the decrease of the Critical Parent from T0 to T1. The F value from the ANOVA table is 3.468. The value for $F 0.05 ; 3.27=$ 2.96 (NIST/SEMATECH e-Handbook of Statistical Methods) is lower than 3.468. This means that the

Table 4: Paired samples test

95\% Confidence interval of the difference

\begin{tabular}{lllllllllll}
\hline & & Mean & $\begin{array}{c}\text { Std. } \\
\text { deviation }\end{array}$ & $\begin{array}{l}\text { Std. } \\
\text { error }\end{array}$ & Lower & Upper & t & d & $\begin{array}{l}\text { Sig. (2- } \\
\text { tailed) }\end{array}$ \\
\hline Pair 1 & CP T2- CP T0 & -.35385 & .39921 & .12624 & -.63942 & -.06827 & -2.803 & 9 & .021 \\
Pair 2 & CP T1-CP T2 & .20000 & .39089 & .12361 & -.07963 & .47963 & 1.618 & 9 & .140 \\
Pair 3 & CP T0-CP T1 & .14640 & .32958 & .05919 & .02551 & .26729 & 2.473 & 3 & .019 \\
\hline
\end{tabular}


hypothesis of the multiple regression is confirmed and that the model is statistically valid.

For the change of the Critical Parent from T0 to T1 the effect of gender and constant is statistically significant and the effect of age and prior TA training is insignificant. The interaction between the constant, representing other variables that weren't controlled for, explains for .976 of the Critical Parent change.

Gender has a direct effect on the change and explains .355 of the change. Females had an average decrease of the mean of 0.15 and the males had an average increase of the mean of 0.21 . The changes on both genders were significant.

Based on the fact that the number of female respondents decreased more from T0 to T1 than the number of males, the females had a stronger influence on the overall Critical Parent decrease. A representation of these results is shown in the following tables.
Figure 1: Estimated marginal means of MEASURE 1: Critical Parent TO-T1

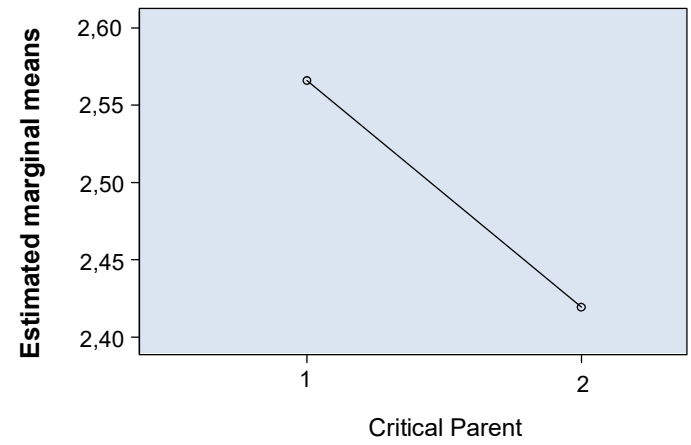

Note. Covariates appearing in the model are evaluated at the following values: gender $=1.2258$, age $=41.0968$, TA training $=1.5387$

Table 5a: ANOVA

\begin{tabular}{llcrrrr}
\hline Model & $\begin{array}{c}\text { Sum } \\
\text { of squares }\end{array}$ & \multicolumn{1}{c}{ df } & $\begin{array}{c}\text { Mean } \\
\text { square }\end{array}$ & F & \multicolumn{1}{c}{ Sig. } \\
\hline & Regression & .906 & 3 & .302 & 3.468 & $.030^{\mathrm{a}}$ \\
$\mathbf{1}$ & Residual & 2.352 & 27 & .087 & & \\
Total & 3.259 & 30 & & & \\
\hline
\end{tabular}

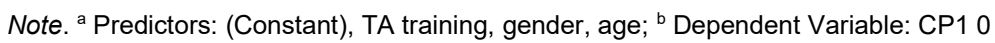

Table 5b: Coefficients ${ }^{a}$

\begin{tabular}{|c|c|c|c|c|c|c|}
\hline & \multirow[b]{2}{*}{ Model } & \multicolumn{2}{|c|}{$\begin{array}{l}\text { Unstandardised } \\
\text { coefficients }\end{array}$} & \multirow{2}{*}{$\begin{array}{c}\begin{array}{c}\text { Standardised } \\
\text { coefficients }\end{array} \\
\text { Beta } \\
\end{array}$} & \multirow[b]{2}{*}{$\mathbf{t}$} & \multirow[b]{2}{*}{ Sig. } \\
\hline & & B & Std error & & & \\
\hline \multirow{4}{*}{1} & (Constant) & -.976 & .342 & & -2.858 & .008 \\
\hline & gender & .355 & .128 & .458 & 2.781 & .010 \\
\hline & age & .006 & .006 & .171 & .979 & .336 \\
\hline & TA training & .075 & .153 & .085 & .490 & .628 \\
\hline
\end{tabular}

Note. ${ }^{a}$ Dependent Variable: CP1 0

Table 6a: One-sample statistics ${ }^{a}-$ female $^{2}$

\begin{tabular}{ccccc}
\hline & Number & Mean & Std. deviation & Std. error mean \\
\hline CP T0 & 30 & 2.4333 & .57261 & .10454 \\
CP T1 & 24 & 2.2885 & .61965 & .12649 \\
\hline
\end{tabular}

Table 6b: One-sample test ${ }^{a}$ - female

Test Value $=0$

\begin{tabular}{ccccc|cc}
\hline \multicolumn{1}{c}{} & \multicolumn{2}{c|}{} & \multicolumn{2}{c}{ 95\% Confidence interval of the difference } \\
\hline & $\mathbf{t}$ & df & Sig. (2-tailed) & Mean Difference & Lower & Upper \\
\hline CP T0 & 23.276 & 29 & .000 & 2.43333 & 2.2195 & 2.6472 \\
CP T1 & 18.093 & 23 & .000 & 2.28846 & 2.0268 & 2.5501 \\
\hline
\end{tabular}




\begin{tabular}{ccccc}
\hline & Number & Mean & Std. deviation & Std. error mean \\
\hline CP T0 & 8 & 2.6538 & .47950 & .16953 \\
CP T1 & 7 & 2.8681 & .38644 & .14606 \\
\hline
\end{tabular}

\begin{tabular}{ccccc|cc}
\hline \multicolumn{8}{c}{ Test Value $=\mathbf{0}$} \\
\hline & & & & \multicolumn{2}{c}{ 95\% Confidence interval of the difference } \\
& $\mathbf{t}$ & df & Sig. (2-tailed) & Mean Difference & Lower & Upper \\
\hline CP T0 & 15.654 & 7 & .000 & 2.65385 & 2.2530 & 3.0547 \\
CP T1 & 19.636 & 6 & .000 & 2.86813 & 2.5107 & 3.2255 \\
\hline
\end{tabular}

Hypothesis 2: There will be a drop in Critical Parent (CP) ego-state at T2 (one month after the training) compared to T0 (beginning of the training).

Hypothesis 0: CP T0 = CP T2

Hypothesis 1: CP T0 > CP T2

The paired sample test showed a $\mathrm{t}=-2.803$ for T0-T2, which is lower than the standard value of $-t$ for Alpha $=.05$ and also because $p$ of .021 is lower than .05 , the null hypothesis is rejected. Therefore the analysis confirms with a probability of $95 \%$ that there is a drop of the Critical Parent ego state from T0 to T2.

The decrease of the ego state from T0 to T2 is shown in Figure 2, and the difference of means is 0.03 .

Figure 2: Estimated marginal means of MEASURE 1: Critical Parent TO-T2

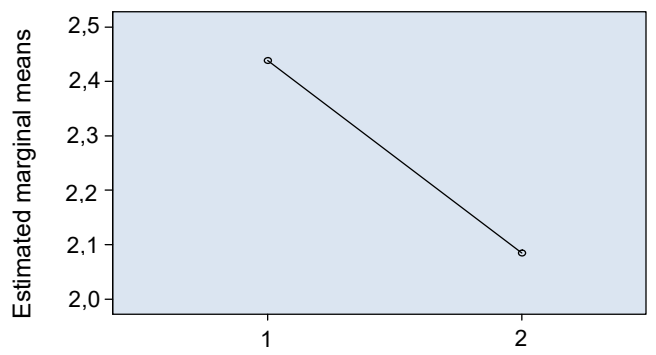

Critical Parent time 3

Hypothesis 3: There will not be any increase in Critical Parent (CP) ego-state at T2 (one month after the training) compared to $\mathrm{T} 1$ (end of the training).

Hypothesis 0: CP T1 = CP T2

Hypothesis 1: CP T1 < CP T2

Considering the fact that $t=1.618$ is not higher than the value of $t$ for Alpha $=.05$ and also that $p$ at .140 is higher than .05 , there is not enough evidence to reject the null hypothesis, so it is accepted. Therefore the hypothesis that there would not be an increase in Critical Parent from T2 to T1 cannot be statistically confirmed.
Table 3 shows there was an increase of Critical Parent from T1 to T2 of 0.22 .

Figure 3: Estimated marginal means of MEASURE 1; Critical Parent T1-T2

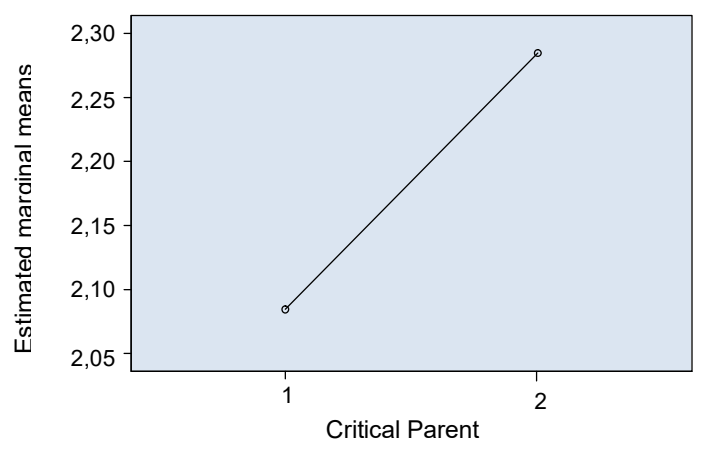

\section{Discussion and limitations}

Discussion

If we take into account Steiner's (2003) argument that in a democratic, cooperative society it is recommended to limit the Critical Parent's control of human affairs, then the TA 101 can be confirmed as a valid instrument that can be used to obtain such a change. The Critical Parent ego state had a statistically confirmed drop after the training session (T1) and this drop was still maintained one month after the session had ended. The research could not confirm the fact that there was no increase of the Critical Parent during the month that passed before the final questionnaires were filled in (T1-T2). If we consider the graph of the changes between T1-T2 we can actually see an increase of the ego state from $\mathrm{T} 1$ to $\mathrm{T} 2$.

The multiple regression results show that gender had a direct effect on changing the Critical Parent. There was a different pattern of change for each gender, with females showing decreased use of Critical Parent whilst males showing an increase. These differences in ego-state change might be explained by the way participants conformed to gender-specific messages 
and norms, which begin during childhood. Maltz and Borker's (1982) research showed that the games children play contribute to socialising children into masculine and feminine cultures. The Critical Parent ego state uses a very strong and strict communication style, which from a social point of view is perceived to be more masculine, while the Nurturing Parent uses a more emotional way of expression that is often regarded as more feminine. For example, according to Tannen (1990) women tend to express agreement and support more often than men, a characteristic that fits with the Nurturing Parent.

Williams (1980) follows the assumption of many TA theorists and states that there is a positive relationship between Critical Parent and Adapted Child. This means that as energy in the Critical Parent decreases so does the psychic energy in the Adapted Child ego state. This research has confirmed a decrease of the Critical Parent after the TA 101 training, but the decrease of the Adapted Child was not statistically significant. If we consider the graphs as evidence of the Adapted Child ego state drop we could argue that there is a decrease between T0-T1 for both Critical Parent and Adapted Child. However this positive relation is not confirmed for T0-T2 because the Adapted Child increases, while the Critical Parent ego state drops.

In this study only three control variables were included. However, the multiple regression used for Critical Parent from T0 to T1 showed that the changes in the ego state were influenced also by other factors that were not controlled for (constant in the coefficients table).

\section{Implications}

The main implication of this research can be considered the empirical study on the effects of TA 101 course on the ego states. During the literature review process for this research no other studies could be found that focused on the effectiveness of the TA 101 course. There are a series of empirical studies (Rosenthal, 2000) regarding a similar process which focuses on transactional analysis therapy, which showed positive results.

\section{Limitations}

It should be noted that this study has several limitations. The most significant one is the number of participants of the TA 101 training that filled in the questionnaires. The initial number was 38; after the training session 31 people filled in the questionnaire; one month later only ten participants responded.

It may also be that similar changes in ego states might result from any course of similar length that focused on teaching psychology to participants.

Regression analysis is normally performed on observed variables; using it here on a created variable of the differences between the means requires that caution must be exercised in applying the results. The different group sizes for the T-test analysis relating to the gender variable also means that caution is called for.

Time was also a limitation of this research because the results had to be collected within three months, from March to May. Since TA 101 trainings are not very common in The Netherlands, finding participants willing to support this research in such a short time was challenging.

In addition, although the TA 101 has a standard syllabus and is run only by qualified trainers, there may well have been differences such as the emphasis placed on the various TA concepts, the models used by the trainers to explain ego states, the permission-giving (Crossman 1966) qualities of the trainers, the relationships the trainers formed with participants, and so on. The composition of the training groups may also have introduced further variables.

Another limitation concerns the cultural background of the participants. This research was carried out in the Netherlands, so certain characteristics of Dutch culture might have influenced the results.

\section{Direction for further research}

The fact that this research could not prove that there was a significant change in self perceptions of four of the five ego states does not necessarily mean that the TA 101 training is ineffective for this purpose. Taking into account the limitations of this study, a longer time for the research might offer the chance to include a larger sample of TA 101 participants.

Another direction for this research might be in testing the effects of TA 101 training directly in an organisational context by including members of the same teams in the course. Knowing each other and having already a relative bond at the beginning of the training, the participants could have better results in applying TA concepts and consequently changing their ego states in the desired direction.

In order to get a better perspective on the interaction between the Critical Parent and the Adapted Child, or between the Nurturing Parent and the Adult, an interesting direction for further research is to study also the interaction between all five ego states. Since these ego states are interconnected, a decrease in one ego state should mean an increase of at least another ego state, but exactly how these changes occur between ego states is still under discussion. Williams (1980) has tested and confirmed some of the interactions initially assumed by Berne, but his findings concerned transactional analysis therapy, not a TA 101 training process.

Finally, future research needs to take into account the plethora of ego-state models that now exist within TA 
literature; the Adjective Check List was developed several years ago against a specific ego-state model that may now be out-dated and which may not have reflected the way ego states are currently taught on TA 101 programmes.

Traian Bossenmayer, MSc Organization Development, HR consultant and trainer, is in TA training as a transactional analyst (Organisational) and can be contacted on traian.bossenmayer@gmail.com

\section{References}

Berne Eric (1967). Transactional Analysis in Psychotherapy. New York: Atherton Press.

Crossman, P. (1966). Permission and Protection Transactional Analysis Bulletin, 5 (19), 152-154.

Dusay, J. M. (1972). Egograms and the constancy hypothesis. Transactional Analysis Journal, 37-41.

Dusay, J. M. (1986). Transactional analysis. In I. L. Kutash \& A. Wolf (Eds.), Psychotherapist's casebook, 413-423. San Francisco: Jossey-Bass.

Erskine, R. \& Trautmann (1981). Ego State Analysis: A Comparative View. Transactional Analysis Journal, 11 (2), 178-185

Erskine, R. \& Trautmann (1988). Ego Structure, Intrapsychic Function and Defense Mechanisms: A Commentary on Eric Berne's Original Theoretical Concepts. Transactional Analysis Journal, 18 (1), 15-19.

Gough \& Heilbrun (1980). The Adjective Check List Manual. Palo Alto: Consulting Psychologist Press.
Hargaden, H. \& Sills, C. (2002). Transactional Analysis A Relational Perspective. Hove: Brunner-Routledge.

Hay, Julie (2009). Transactional analysis for trainers. Hertford: Sherwood Publishing.

Maltz, D. \& Borker, R. (1982). A cultural approach to malefemale miscommunication. In J. Gumperz (Ed.), Language and social identity, 196-216. Cambridge, UK: Cambridge University Press.

NIST/SEMATECH e-Handbook of Statistical Methods, http://www.itl.nist.gov//div898/handbook/eda/section3/ed a3673.htm/ Accessed on 31/12/2010.

Pearson, J. (1983). Interpersonal Communication. Glenview, Illinois: Scott, Foreman and Company.

Rosenthal, W. S. (2000). Relationship of Change in EgoState to Outcome of Stuttering Therapy: Preliminary Findings. Hayward: California State University.

Steiner C. (2003). Emotional Literacy; Intelligence with a Heart. Fawnskin, CA: Personhood Press.

Tannen, Deborah (1990, June 24). Sex, Lies and Conversation; Why Is It So Hard for Men and Women to Talk to Each Other? The Washington Post.

Van Beekum, Servaas (1996). The graphics of Ego States. Advanced Working Conference, Amsterdam, Netherlands.

Williams, K. B. \& Williams, J. E. (1980). The assessment of transactional analysis ego states via the Adjective Check List. Journal of Personality Assessment, 2, 120-129. 